\title{
Service vs Transformation: A Comparative Study of Two Kinds of Leadership Behaviors on Work Engagement
}

\author{
Jingxuan Zhou \\ School of Management, Wuhan University of Technology, Wuhan, P. R. China \\ 402222817@qq.com
}

\begin{abstract}
Keywords: Service-oriented leadership: Transformational leadership: Employee trust; Organizational uncertainty; Work engagement
\end{abstract}

\begin{abstract}
It has always been the core issue of leadership research to stimulate employees' work engagement through leadership behavior. However, previous research has focused solely on single leadership behavior, ignoring the complexity of the dual leadership behavior in an organizational context. This paper mainly discusses the impact of service-oriented and transformational leadership behaviors on employee work engagement and its potential mechanism. The results show that both service-oriented and transformational leadership have significant positive impacts on employee trust and employee engagement; and employee trust plays an intermediary role in both service-oriented and transformational leadership. In addition, the influence of two leadership behaviors on employee trust is regulated by organizational uncertainty. From the perspective of bottom-up, this paper constructs a driving model of leadership's influence on employee engagement with a combination of psychological effect and organizational situation effect, providing certain reference basis for enterprise leaders to stimulate employee engagement.
\end{abstract}

\section{Introduction}

The dual impact of organizational uncertainty and employee psychological trends is a new challenge for enterprise human resource management under the new normal. How to lead the enterprise out of the predicament, how to stimulate employees' work engagement, enterprise leadership behavior has become a top priority. The importance of leadership directly induces the upsurge of leadership research, which makes the leadership theory extremely exuberant. During this period, the emergence of two leadership behaviors was particularly striking. One is transformational leadership and the other is service-oriented leadership. These two leadership behaviors have a profound impact on the work engagement of Chinese enterprise employees. The research features of this paper are as follows: First, the study of single leadership behavior is abandoned, and the comparative study of dual leadership that has received much attention is selected. Secondly, attention should be paid to the difference of the psychological effects of transformational leadership and service-oriented leadership on employees' job engagement. It differentiates employee trust into two categories: emotional trust and ability trust, and constructs the dual path of employee engagement. Thirdly, considering the situational effect under organizational uncertainty, the identification of the resulting "path variation" is not only rich in theoretical significance, but also has profound practical significance.

\section{Literature Review and Research Hypotheses}

Connotation of Leadership Behavior. The concept of transformational leadership originated with Burns. He believes that transformational leadership is the motivation of leaders to motivate and inspire employees through higher ideological and moral values, so that subordinates can fully devote themselves to work, and then promote subordinates to become leaders, while leaders become the driving force of reform. It is a process in which leaders and subordinates promote each other to a higher level of need and motivation (Burns, 1978).Later, transformational leadership was developed by Bass. He believed that transformational leadership is a process in which leaders and members enhance morality and motivation to a higher level, which will lead employees to trust, 
respect and loyalty to leaders. Transformational leaders guide subordinates to go beyond their own interests and pursue higher goals by changing their values and beliefs. Bass and Avolio further proposed four key factors of the transformational leadership model, including: (1) glamour impact; (2) motivational incentives; (3) intellectual inspiration; (4) individual care (Bass \& Avolio, 1993).

Service-oriented leadership was first proposed by Greenleaf. He believed that the leader should first be a servant or a service provider, and he should have the initiative desire to serve others and meet their needs, so as to gain the trust of his followers and form the leadership for followers (Greenleaf, 1991). Greenleaf regards "transcending self-interest" as the core feature of service-oriented leadership. Service-oriented leadership is chosen for leadership because of the tremendous support of employees, because service-oriented leadership gives them commitment and reliability. Make employees the best by creating a service-oriented atmosphere. An important aspect of Greenleaf's service-oriented leadership is that he or she doesn't use power to get things done, but tries to persuade and trust employees. According to Liden, service-oriented leadership should include seven dimensions: conceptual skills, willingness to empower, helping subordinates grow and succeed, giving priority to subordinates, ethical behavior, emotional comfort, and creating value for the community (Liden, 2008).

Leadership Behavior and Work Engagement. Transformational leadership can stimulate the work motivation of subordinates, give them more autonomy, and give them personalized care, which enhances their work enthusiasm and helps them focus on their work. Through the vision of motivation, the transformational leadership describes the organization's beautiful vision, motivates the employees, and feels the value of the work, making them willing to meet the challenges, undertake more tasks, and invest more in the work. Some studies also show that transformational leadership is positively correlated with work engagement. In addition, transformational leadership can improve employees' recognition of work and organization, so employees feel that work is more meaningful, and that serious work makes greater contribution to the organization, thereby increasing the level of work engagement. Transformational leader cares about the individual needs of employees, provide more training opportunities to help employees develop skills. At the same time, through positive feedback, employees can have higher psychological security and have more confidence in the feasibility of tasks, thus showing more dynamic, dedicated and focused working state (Zhu, Avolio \& Walumbwa. 2008). Based on this, we believe that:

Hla: transformational leadership has a significant positive effect on work engagement

As a kind of leadership method with service subordinates as the main task, service-oriented leaders are committed to safeguarding the interests of subordinates, stimulating their potential, giving consideration to the overall development of subordinates while realizing the economic benefits of the organization, and regard the development of subordinates as one of the goals that cannot be ignored by the organization. As service-oriented leaders focus on the interests of subordinates and often go beyond their personal interests to meet their physical, psychological and emotional needs, such attitudes and behaviors of leaders towards subordinates will inevitably inspire their gratitude, and then they will adopt the way of improving work engagement to repay their leaders. Social exchange theory believes that as an object of direct contact with employees, leaders and their behaviors are often the measurement standard of employees' organizational exchange. Service-oriented leadership can provide employees with rich emotional resources and work support, and employees will return higher work engagement level. In the process of individual return to the organization, employees are more self-devoted and contribute time and energy to the organization and work. Based on this, we believe that:

Hlb: Service-oriented leadership has a significant positive effect on work engagement

The Intermediary Role of Employee Trust. Trust is a state of mind in which individuals are willing to expose their weaknesses to others based on positive expectations of the intentions and actions of others without fear of being exploited (Rousseau, 1998). Of course, there are different definitions of trust and different dimensions of trust. However, most trust researchers classify trust as cognitive and emotional (McAllister, 1995). 
There are two different theoretical perspectives on leadership trust (Dirks \& Ferrin, 2002): the feature view and the relationship view. Cognitive trust is more likely to be associated with the feature view, whereas emotional trust is more likely to be associated with the relational view. The feature view focuses on the perception of leadership, quality and their effects. Leaders have the power to influence subordinates' promotion, work arrangement and salary distribution, etc.., so subordinates pay attention to leaders, and through rational reasoning, judge whether the leaders have the ability to handle affairs and manage, whether they are upright and reliable, and thus affect their work attitude and behavior; The relational view pays attention to the nature of the relationship between the superior and the subordinate, and emphasizes that the superior and the subordinate form a high-quality relationship transcends the pure economic contract. Employees feel that what the leader has shown or will show concern for their own interests in the future, which can promote the development of leadership emotional trust. This trust makes employees more willing to engage in social exchange(Aryee, 2002).

$\mathrm{H} 2 \mathrm{a}$ : transformational leadership has a significant positive impact on employee trust

$\mathrm{H} 2 \mathrm{~b}$ : service-oriented leadership has a significant positive impact on employee trust

H2c: employee trust plays an intermediary role between service-oriented leadership and work engagement

$\mathrm{H} 2 \mathrm{~d}$ : employee trust plays a mediating role between transformational leadership and work engagement

Regulation of Organizational Uncertainty. Organizational uncertainty refers to employees' perception of the degree of uncertainty in organizational survival based on their subjective choice of organization-related information (Choi\&MaiDalton, 1999). There are more difficulties and even crises in the highly uncertain organizational situation, which requires people to pay a higher level of effort and engagement, and have higher flexibility and adaptability. Such a situation will also bring greater challenges and more opportunities for change, requiring a new understanding and response from the organization members (De Hoogh, 2005). Uncertainty identity theory (Hogg, 2007) argues that people reduce uncertainty by interacting with social groups. Social groups provide security, resources and support, so people seek group connections or strong organizational identification during periods of high uncertainty, As a result, when followers tend to focus on the uncertainty of groups and organizations that exceed their own comfort and safety, we believe that the collective or organizational needs are appreciated by followers, while the individual needs become less prominent, and psychological needs become more satisfying. More oriented to meeting the needs of the organization rather than individual needs. In times of uncertainty, conformity is often ineffective because decisions must be made quickly in crisis management or uncertain events. At this point, the leader often uses unconventional means to achieve their goals and achieve heroism. In summary, the occurrence of uncertain events urges leaders to emphasize organizational needs and behaviors that are not logical and decisive. Transformational leaders meet this need better than service leaders. We believe that service-oriented leadership has a very different adaptability to organizational uncertainty. There is a tendency to focus on organization or production rather than on individuals. The need for personal bonding service leadership becomes weaker during uncertain times (Cohen, Solomon, 2004). As a result,

H3a: organizational uncertainty plays a moderating role in service-oriented leadership and employee trust

$\mathrm{H} 3 \mathrm{~b}$ : organizational uncertainty plays a moderating role in transformational leadership and employee trust

\section{Research Methods and Research Process}

Research Sample. The data of this paper was collected in many cities such as Guangzhou and Shanghai. Reduce the social appreciative problems caused by sensitivity problems through the methods distributed by acquaintances. Before the distribution of the formal questionnaire, we first made a prediction test to ensure the accuracy of the relevant items. 
The official questionnaire was collected from September 2017 to December 2017. A total of 400 questionnaires were issued and 348 valid questionnaires were recovered, with a recovery rate of $87 \%$. In terms of gender, $52 \%$ were men and $48 \%$ were women. In terms of age, $8 \%$ are under 20 years old, $40 \%$ are $20-29$ years old, $30 \%$ are $30-39$ years old, $18 \%$ are $40-49$ years old, and 3\% are over 50 years old. In terms of education, senior high school and lower $10 \%$, junior college accounting for $20 \%$, undergraduate accounting for $40 \%$, master degree and above accounting for $30 \%$; In terms of positions, ordinary employees accounted for $40 \%$, grassroots management personnel accounted for $30 \%$, middle management personnel accounted for $20 \%$ and top management accounted for $10 \%$.

Statistical Methods and Variable Measurement. All statistical analyses were performed using SPSS20.0 and MPLUS6.0.

Transformational leadership: the scale compiled by Li Chaoping (2005) is adopted, including four dimensions of morality, leadership charm, vision motivation and individualized care, with a total of 26 items. Service-oriented leadership: 15 predictive items, including altruistic sense of purpose, emotional comfort, predictive intelligence, persuasion guidance and social responsibility, were adopted in the scale compiled by Sun Jianmin. Employee trust: refer to the trust scale of McAllister(1995), including two dimensions of cognitive trust and emotional trust, with a total of 11 items. Work engagement: refer to Schaufeli(2006)scale, including three dimensions of vitality, dedication and concentration, with a total of 9 items. Organizational uncertainty: refer to Choi and MaiDalton(1998), there are three items, which respectively indicate that our enterprise is in crisis; Our corporate performance suffered a serious decline: Our business environment is favorable. Control variables: the researchers selected four demographic variables commonly found in organizational behavior-gender, age, education and position.

\section{Data analysis and results}

Reliability and Validity Analysis. We first analyzed the scale data using the most widely accepted Cronbach's $\alpha$ value, because the data analysis of the scale was reliable only when the reliability was accepted. The results are shown in Table 1. The data in Table 1 show that all the coefficients indicate that the scale in this study has good internal consistency reliability.

Secondly, in order to test the structural validity of all the variables in our study, we used SPSS20.0 to conduct exploratory factor (EFA) analysis on the indicator data. The specific structure of the analysis results is shown in Table 1. All the variables were tested by Bartlett's spherical test $(\mathrm{p}<0.000$ ), and the KMO values were all above 0.8 , indicating that the data basically met the conditions of factor analysis and had good structural validity.

Table 1 Reliability of scale

\begin{tabular}{cccc}
\hline Variable & Cronbach's $\alpha$ & KMO & Bartlett's spherical test \\
\hline $\begin{array}{c}\text { service-oriented } \\
\text { leadership }\end{array}$ & 0.85 & 0.83 & $156.131(\mathrm{p}<0.000)$ \\
$\begin{array}{c}\text { transformational } \\
\text { leadership }\end{array}$ & 0.87 & 0.88 & $156.131(\mathrm{p}<0.000)$ \\
$\begin{array}{c}\text { employee trust } \\
\text { organizational }\end{array}$ & 0.80 & 0.90 & $156.131(\mathrm{p}<0.000)$ \\
$\quad$ uncertainty & 0.90 & 0.85 & $156.131(\mathrm{p}<0.000)$ \\
work engagement & 0.86 & 0.82 & $156.131(\mathrm{p}<0.000)$ \\
\hline
\end{tabular}

Thirdly, on the basis of exploratory factor analysis (EFA) process, Mplus 6.0 was used to verify factor analysis (CFA) of latent variables. The results of the analysis are shown in Table 2 . It can be seen from the fitting index that the factor structure fits the data well and lays a foundation for further research. At the same time, we also observed several indicators on the actual data fitting. The first model is superior to the other four models, showing that the five variables used in this study are well differentiated. 
Table 2 Results of confirmatory factor analysis for construct discrimination validity

\begin{tabular}{|c|c|c|c|c|c|}
\hline Model & Factor & X2/df & CFI & TLI & RESEA \\
\hline Model1 & TL;SL;T;O;E & 2.14 & 0.91 & 0.90 & 0.05 \\
\hline Model2 & TL+SL;T;O;E & 2.86 & 0.85 & 0.82 & 0.07 \\
\hline Model3 & TL+SL;T+O;E & 3.58 & 0.80 & 0.77 & 0.11 \\
\hline Model4 & TL+SL;T+O+E & 4.65 & 0.72 & 0.68 & 0.13 \\
\hline Model5 & TL+SL+T+O+E & 6.44 & 0.57 & 0.52 & 0.16 \\
\hline
\end{tabular}

Descriptive Statistics of Variables. The mean, standard deviation and correlation coefficient of each variable are shown in Table 3. There were significant positive correlation between transformational leadership and employee trust $(\mathrm{r}=0.70, \mathrm{P}<0.01)$, job involvement $(\mathrm{r}=0.31, \mathrm{P}<$ $0.01)$, service leadership and employee trust $(\mathrm{r}=0.60, \mathrm{P}<0.01)$, job involvement $(\mathrm{r}=0.28, \mathrm{P}<$ $0.01)$, and employee trust and job involvement $(\mathrm{r}=0.40, \mathrm{P}<0.01)$. The above results initially support the assumptions we have made.

Table 3 The mean, standard deviation and correlation coefficient of each variable

\begin{tabular}{cccccccc}
\hline Variable & M & SD & 1 & 2 & 3 & 4 & 5 \\
\hline $\begin{array}{c}\text { transformational } \\
\text { leadership }\end{array}$ & 3.59 & 0.84 & $(0.89)$ & & & & \\
$\begin{array}{c}\text { service-oriented } \\
\text { leadership }\end{array}$ & 3.35 & 0.80 & 0.30 & $(0.80)$ & & & \\
$\begin{array}{c}\text { employee trust } \\
\text { organizational }\end{array}$ & 3.19 & 0.96 & $0.70 * *$ & $0.60 * *$ & $(0.82)$ & & \\
$\quad$ uncertainty & & 0.93 & $0.55 * *$ & $0.65 * *$ & $0.40 * *$ & $(0.85)$ & \\
work engagement & 3.5 & 0.88 & $0.31 * *$ & $0.28 * *$ & $0.30 * *$ & 0.22 & $(0.78)$ \\
\hline
\end{tabular}

Note: ${ }^{*} \mathrm{p}<0.05, * * \mathrm{p}<0.01$, the same below; The numbers in brackets on the diagonal represent the internal consistency of the scale

Hierarchical Regression Analysis. In this study, hierarchical regression analysis was used to test the above hypothesis. The results are shown in tables 4 and 5.

It can be seen from M2 that transformational leadership has a significant positive impact on work input $(\beta=0.35, \mathrm{p}<0.01)$; service leadership also has a significant positive impact on work input $(\beta=0.26, \mathrm{p}<0.01)$. , H1a and $\mathrm{H} 2 \mathrm{~b}$ are verified. M3 showed that transformational leadership had a significant positive effect on employee trust (beta $=0.32, \mathrm{P}<0.001$ ), and service leadership had a significant positive effect on employee trust (beta $=0.35, \mathrm{P}<0.001$ ). H2a and $\mathrm{H} 2 \mathrm{~b}$ have been verified. After putting service-oriented leadership, transformational leadership and employee trust into the regression model, we can see from M4 that employee trust has a significant positive impact on job involvement under the transformational leadership path (beta $=0.38, \mathrm{P}<0.01$ ); under the service-oriented leadership path, employee trust also has a significant positive impact on work involvement $(\mathrm{M} 7, \beta=-0.22, \mathrm{p}<0.01)$. 
Table 4 The predictive effect of two leadership behaviors on work engagement: the mediating effect of employee trust

\begin{tabular}{|c|c|c|c|c|c|c|c|c|}
\hline & \multicolumn{3}{|c|}{ work engagement } & \multicolumn{5}{|c|}{ employee trust } \\
\hline & M1 & M2 & M3 & M4 & M5 & M6 & M7 & M8 \\
\hline Control Variable & & & & & & & & \\
\hline Gender & 0.13 & 0.10 & 0.11 & 0.11 & 0.13 & 0.10 & 0.11 & 0.11 \\
\hline Age & 0.10 & 0.13 & 0.11 & 0.11 & 0.10 & 0.13 & 0.11 & 0.11 \\
\hline Education & 0.10 & 0.08 & 0.08 & 0.07 & 0.10 & 0.08 & 0.08 & 0.07 \\
\hline Position & 0.08 & 0.08 & 0.07 & 0.07 & 0.08 & 0.08 & 0.07 & 0.07 \\
\hline Independent Variable & & & & & & & & \\
\hline Transformational leadership & & $0.35 * *$ & 0.07 & & $0.32 * *$ & & & \\
\hline Service-oriented leadership & & $0.26 * *$ & 0.05 & & $0.35 * *$ & & & \\
\hline $\begin{array}{c}\text { Mediating Variable } \\
\text { employee trust } \\
\text { (Transformational leadership) }\end{array}$ & & & $0.38 * *$ & $0.30 * *$ & & & & \\
\hline $\begin{array}{l}\text { employee trust } \\
\text { (Service-oriented leadership) }\end{array}$ & & & $0.42 * *$ & $0.20 * *$ & & & & \\
\hline$\Delta \mathrm{R} 2$ & 0.05 & $0.05 * *$ & $0.09 * *$ & $0.05 * *$ & & & & \\
\hline $\mathrm{R} 2$ & 0.05 & 0.09 & 0.15 & 0.15 & & & & \\
\hline $\mathrm{F}$ & 2.5 & $4.84 * *$ & $6.10 * *$ & $5.45 * *$ & & & & \\
\hline
\end{tabular}

Table 5 The predictive effect of two leadership behaviors on work engagement: Regulation of organizational uncertainty

\begin{tabular}{ccccc}
\hline & \multicolumn{4}{c}{ employee trust } \\
\hline & M1 & M2 & M3 & M4 \\
\hline Control Variable & & & & \\
Gender & -0.13 & -0.10 & -0.11 & -0.11 \\
Age & 0.10 & 0.13 & 0.11 & 0.11 \\
Education & -0.10 & -0.08 & -0.08 & -0.07 \\
Position & 0.08 & 0.08 & 0.07 & 0.07 \\
\hline $\begin{array}{c}\text { Independent Variable } \\
\text { Transformational leadership }\end{array}$ & $0.36^{* *}$ & $0.23^{* *}$ & $0.39^{* *}$ \\
Service-oriented leadership & & $0.30^{* *}$ & $0.33^{* *}$ & $0.35^{* *}$ \\
\hline $\begin{array}{c}\text { Regulated Variable } \\
\text { organizational uncertainty }\end{array}$ & & & 0.05 & 0.06 \\
interaction effect & & & & \\
\hline $\begin{array}{c}\text { Transformational leadership* } \\
\text { organizational uncertainty }\end{array}$ & & & & \\
\hline $\begin{array}{c}\text { Service-oriented leadership* } \\
\text { organizational uncertainty }\end{array}$ & & & & $-0.31^{* *}$ \\
\hline$\Delta R 2$ & 0.31 & $0.37^{* *}$ & $0.00^{* *}$ & $0.04^{* *}$ \\
R2 & 0.22 & 0.37 & 0.37 & 0.42 \\
F & 10.00 & $23.84^{* *}$ & $20.00^{* *}$ & $20.45^{* *}$ \\
\hline
\end{tabular}

\section{Conclusion and discussion}

From a bottom-up perspective, this paper constructs a driving model of leadership's influence on employee involvement, which has both psychological effect and organizational context effect, and provides a certain reference for enterprise leaders to stimulate employee involvement. The study found that service-oriented leadership and transformational leadership have a significant positive impact on employee trust and employee engagement; employee trust plays a mediating role in 
service leadership and transformational leadership. In addition, the impact of the two leadership behaviors on the work involvement is regulated by the organizational environment. Regrettably, employee trust is often divided into cognitive trust and emotional trust by scholars. Transformational leadership and service leadership should be matched with each other in theory. However, due to time constraints and sample limitations, the author of this paper fails to deeply explore the different roles of different leaders through different types of trust and its evolution mechanism under organizational uncertainty.

\section{References}

[1] De Hoogh, A. H. B., Hartog, D. N. D., \& Koopman, P. L.(2005). Linking the Big Five-Factors of personality to charismatic and transactional leadership; Perceived dynamic work environment as a moderator. Journal of Organizational Behavior, 26, 839-865.

[2] Hogg, M. A. (2007). Uncertainty-identity theory. Advances in Experimental Social Psychology, $39,69-126$.

[3] Humphreys, J. H. (2005). Contextual implications for transformational and servant leadership. A historical investigation. Management Decision, 43, 1410-1431.

[4] Liden R C, Wayne S J, Zhao H, et al.(2008)Servant leadership: Development of a multidimensional measure and multi-level assessment. The Leadership Quarterly, 19: 161-177.

[5] Mayer, C. R., \& Gavin, M. B. (2005). T rust in management and performance: who minds the shop while the employees watch the boss? Academy of Management Journal, 48, $874-888$.

[6] Walumbwa, F. Avolio, B, \& Zhu, W. (2008), How transformational leadership weaves its influence on individual job performance: The role of identification and efficacy beliefs [J]. Personnel Psychology, 61(4), 793-825. 